\title{
Implementasi Pembangunan Jalan Tol Ruas Padang-Sicincin dari Aspek Pengadaan Tanah
}

\author{
${ }^{1}$ Wahyu Putri Arifah, ${ }^{2}$ Nora Eka Putri \\ ${ }^{12}$ Universitas Negeri Padang, Indonesia \\ e-mail: wahyuputiarfah@gmail.com
}

\begin{abstract}
Abstrak
Pembangunan jalur bebas hambatan (jalan tol) terus mengalami peningkatan yang cukup signifikan di seluruh wilayah Indonesia. Keberadaannya juga diperhitungkan, menimbang manfaat yang akan dirasakan terutama dari segi ekonomi. Dan untuk mewujudkan hal tersebut, dibutuhkan lahan yang luas demi kelancaran pembangunan yang telah direncanakan melalui pengadaan tanah. Namun dalam pengadaan tanah tidak terlepas dari kendala-kendala terutama persoalan ganti kerugian, salah satunya jalan tol ruas Padang-Sicincin yang berada di Kabupaten Padang Pariaman yang terkendala karena masih banyak masyarakat yang tidak setuju dengan nilai tanah yang dikeluarkan oleh tim appraisal serta tumpang tindih kepemilikan lahan antara pemilik sertifikat dengan penggarap lahan. Tujuan dari penelitian ini yaitu untuk mengetahui sejauh mana implementasi pembangunan jalan tol ruas PadangSicincin dilihat dari aspek pengadaan tanah. Penelitian ini merupakan penelitian kualitatatif. Untuk informan penelitian, ditentukan dengan teknik purposive sampling dan accidental sampling. Teknik pengumpulan data berupa observasi, wawancara, dan dokumentasi. Berdasarkan hasil penelitian, pengadaan tanah untuk pembangunan jalan tol ruas Padang-Sicincin sudah sesuai dengan undangundang pengadaan tanah dan petunjuk teknis pengadaan tanah. Kendala yang terjadi, sudah diupayakan oleh Pemerintah Kabupaten Padang Pariaman untuk dicarikan solusinya, namun belum maksimal.
\end{abstract}

Keywords: Implementasi, Pengadaan Tanah, Pembangunan Jalan Tol

\begin{abstract}
The construction of expressways (toll roads) continues to experience a significant increase in all regions of Indonesia. Its existence is also taken into account, considering the benefits that will be felt primarily in terms of economics. And to realize this, vast land is needed for the smooth development that has been planned through land acquisition. However, land acquisition is inseparable from obstacles, especially compensation issues, one of which is the Padang-Sicincin toll road in Padang Pariaman which is constrained because there are still many people who do not agree with the land value issued by the appraisal team and overlapping ownership. land between the certificate holder and the land tiller. The purpose of this study is to determine the extent of the implementation of the Padang-Sicincin toll road construction in terms of land acquisition aspects. This research is a qualitative research. For research informants, determined by purposive sampling and accidental sampling techniques. Data collection techniques in the form of observation, interviews, and documentation. Based on the research results, land acquisition for the construction of the Padang-Sicincin toll road is in accordance with the land acquisition law and the technical land acquisition guidelines. Constraints that have occurred have been sought by the Padang Pariaman District Government to find a solution, but this has not been maximized.
\end{abstract}

Kata Kunci : Implementation, Land Procurement, Toll Road Development 


\section{PENDAHULUAN}

Tanah berperan penting sebagai salah satu aset vital bagi kelangsungan hidup manusia. Akan tetapi, semakin lama kebutuhan terhadap tanah terus meningkat disebabkan laju pertumbuhan penduduk yang pesat dan kebutuhan lain yang berkaitan langsung dengan tanah. Bagi suatu bangsa, keberadaan tanah dijadikan sebagai sarana untuk mencapai kesejahteraan terutama untuk rakyat. Dan untuk mencapai kesejahteraan tersebut, dapat diwujudkan melalui pembangunan.

Kebutuhan terhadap tanah terutama untuk pembangunan infrastruktur bagi kepentingan umum dilakukan melalui pengadaan tanah oleh pemerintah. Dan kepentingan umum dapat diartikan sebagai kepentingan bagi banyak orang terutama masyarakat. Pengadaan tanah bagi kepentingan umum diatur dalam UU Nomor 2 Tahun 2012 tentang Pengadaan Tanah Bagi Pembangunan Untuk Kepentingan Umum. Pengadaan tanah untuk kepentingan umum salah satunya digunakan dalam pembangunan jalan tol, yaitu jalur bebas hambatan berbayar yang disediakan secara khusus untuk kendaraan jenis tertentu. Keberadaannya diharapkan dapat berpengaruh terhadap roda perekonomian masyarakat khususnya pada sektor pertanian, industri serta pariwisata.

Di Indonesia, saat ini sedang gencarnya dilakukan pembangunan jalan tol di berbagai daerah, salah satunya Pembangunan Jalan Tol Padang-Pekanbaru yang terdiri atas enam seksi yakni Padang-Sicincin, Sicincin-Bukittinggi, Bukittinggi-Payakumbuh, Payakumbuh-Pangkalan, Pangkalan-Bangkinang dan akan berakhir di Bangkinang-Pekanbaru. Pembangunan Jalan Tol Padang-Pekanbaru ini sempat terhenti selama setahun terakhir ini karena adanya kendala dalam pembebasan lahan.

Untuk jalan tol seksi Padang Sicincin ini, panjangnya mencapai 28 kilometer (CNN Indonesia, Juni 2019/diakses pada tanggal 23 Juli 2019). Dan dalam proses pembebasan lahan masih terjadi beberapa masalah diantaranya masih banyaknya masyarakat yang belum setuju mengenai ganti rugi pembebasan lahan. Masyarakat menganggap bahwa harga ganti rugi yang diberikan masih terlalu rendah dimana proses ganti rugi tersebut sebelumnya telah dilakukan penilaian terlebih dahulu oleh penilai (appraisal) dalam menetapkan harga tanah (Bisnis.com, Januari 2019/diakses pada tanggal 15 Maret 2019). Dalam menentukan harga tanah, salah satunya dihitung berdasarkan nilai pasar dan nilai lainnya yang dapat dihitung. Namun begitu, masyarakat masih keberatan terhadap nilai yang sudah dikeluarkan. Dengan demikian dapat dilihat bahwa antara keinginan masyarakat dan penetapan dari tim appraisal tidak sama.

Berdasarkan penelitian awal yang dilakukan, permasalahan yang penulis temukan di Kantor Badan Pertanahan Nasional Kabupaten Padang Pariaman, lahan yang sudah dalam proses pembebasan baru mencapai 4,2 kilometer tepatnya berada pada Nagari Kasang Kecamatan Batang Anai Kabupaten Padang Pariaman. Lamanya proses pembebasan lahan dikarenakan masyarakat tidak sepakat dengan harga ganti rugi yang telah ditetapkan oleh tim appraisal karena dinilai terlalu rendah, serta masih terjadinya tumpang tindih kepemilikan lahan antara pemilik sertifikat dan penggarap lahan.

Terkait dengan permasalahan-permasalahan yang telah diuraikan diatas, maka penulis ingin mendalami bagaimana implementasi pembangunan jalan tol ruas Padang-Sicincin dilihat dari aspek pengadaan tanah.

Teori dalam penelitian ini bersumber dari (Peraturan Kepala BPN Republik Indonesia Nomor 5 Tahun 2012 tentang Petunjuk Teknis Pelaksanaan Pengadaan Tanah, 2012) yang terdiri dari 10 tahap yaitu penyiapan pelaksanan, inventarisasi dan identifikasi, penetapan penilai, musyawarah penetapan bentuk ganti kerugian, pemberian ganti kerugian, pemberian ganti kerugian dalam keadaan khusus, penitipan ganti kerugian, pelepasan objek pengadaan tanah, pemutusan hubungan hukum antara pihak yang berhak dengan objek pengadaan tanah serta pendokumentasian peta bidang, daftar nominatif, dan data administrasi pengadaan tanah.

Menurut World Bank (Noor, 2019:361) infrastruktur terbagi atas 3 bagian, yaitu : (1) Infrastruktur ekonomi, berupa pembangunan fisik yang mendukung kegiatan perekonomian seperti jalan, pelabuhan, 
bandara, listrik, irigasi, bendungan, jembatan, dan lain sebagainya. (2) Infrastruktur sosial, yang lebih mengarah pada pembangunan manusia dan lingkungannya seperti pendidikan, kesehatan, rekreasi, perumahan, dan lainnya. (3) Infrastruktur administrasi, berupa kontrol administrasi, penegakan hukum, dan koordinasi.

Jalan tol merupakan jalur bebas hambatan berbayar yang disediakan secara khusus untuk kendaraan jenis tertentu. Pembangunan jalan tol bertujuan untuk meningkatkan aksesibilitas dan kapasitas jaringan jalan dalam melayani lalu lintas. Keberadaan jalan tol dapat menunjang kegiatan perekonomian melalui kegiatan distribusi barang dan jasa baik antar kabupaten/kota maupun antar provinsi.

\section{METODE}

Penelitian ini menggunakan metode kualitatif. Menurut (Sugiyono, 2017:9) mendefinisikan metode penelitian kualitatif sebagai metode penelitian yang berlandaskan postpositivisme, digunakan untuk meneliti pada kondisi obyek yang alamiah (sebagai lawannya adalah eksperimen) dimana peneliti adalah sebagai instrumen kunci, teknik pengambilan data dilakukan secara triangulasi (gabungan), analisis data bersifat induktif/kualitatif dan hasil penelitian kualitatif lebih menekankan makna dari pada generalisasi. Lokasi penelitian ini berada di Kabupaten Padang Pariaman. Informan dalam penelitian ini terdiri dari Kepala Sub Seksi Fasilitasi Pengadaan Tanah dan Penetapan Pemerintah Badan Pertanahan Nasional Kabupaten Padang Pariaman, Pejabat Pembuat Komitmen (PPK) Pengadaan Tanah, Sekda Kabupaten Padang Pariaman yang diwakili Asisten Administrasi Umum Sekda Kabupaten Padang Pariaman, Kepala Bidang Tata Ruang Dinas PUPR Kabupaten Padang Pariaman, Wali Nagari Kasang, Wali Nagari Sicincin, dan masyarakat yang terdampak jalan tol dengan melakukan pendekatan teknik purposive sampling dan accidental sampling. Menurut (Ahmadi, 2014), purposive sampling dimaksudkan untuk menentukan informan-informan yang mewakili sejumlah informasi yang dibutuhkan dalam penelitian

Tahap-tahap dalam penelitian melalui beberapa tahap yaitu studi kepustakaan, tahap pra lapangan, tahap pekerjaan lapangan, dan tahap pasca lapangan/ tahap analisis data. Sumber data yang digunakan adalah data primer dan data sekunder. Teknik pengumpulan data yang digunakan adalah data primer dan data sekunder. Teknik pengumpulan data yang digunakan adalah observasi, wawancara, dan dokumentasi. Dalam penelitian ini teknik penguji keabsahan data yang digunakan adalah teknik triangulasi sebab data yang diperoleh merupakan data dari berbagai banyak sumber.

\section{HASIL DAN PEMBAHASAN}

\subsection{Penyiapan Pelaksanaan}

Badan Pertanahan Nasional Kabupaten Padang Pariaman merupakan pihak yang bertanggungjawab dalam pelaksanaan pengadaan tanah untuk pembangunan jalan tol ruas Padang-Sicincin. Namun demikian, juga terdapat pihak-pihak lain yang saling terkait seperti PPK Pengadaan Tanah, Pemkab Padang Pariaman, Dinas PUPR Kabupaten Padang Pariaman, serta Camat dan Wali Nagari. Semua tahapan dalam penyiapan pelaksanaan dilaksanakan oleh BPN Kabupaten Padang Pariaman dilakukan melalui rapat antar panitia maupun satuan tugas yang sudah ditunjuk. Dan hampir tidak terdapat kendala teknis yang berarti. 


\subsection{Inventarisasi dan Identifikasi}

Dalam tahap ini cukup banyak masyarakat yang keberatan dengan hasil inventarisasi dan identifikasi tersebut dikarenakan beberapa hal seperti tidak cocoknya luas tanah yang diharapkan masyarakat dengan hasil ukur dari petugas BPN Kabupaten Padang Pariaman serta kurang cermatnya petugas dalam menghitung jumlah tanaman. Namun masalah tersebut sudah diatasi oleh Satgas yang ditunjuk.

\subsection{Penetapan Penilai}

Dalam pengadaan tanah untuk pembangunan jalan tol Padang-Sicincin ini, penilai disediakan oleh Tim PPK Pengadaan Tanah dan akan dipilih dan ditetapkan atas persetujuan BPN. Dan yang ditunjuk untuk menjadi tim penilai (appraisal) adalah dari Kantor Jasa Penilai Publik MBPRU.

Berdasarkan wawancara dengan tim appraisal KJPP MBPRU, secara garis besar ada tiga tahap dalam proses penilaian yaitu lingkup penugasan, implementasi, dan laporan penilai. Dalam menghitung nilai tanah di istilahkan dengan nilai penggantian wajar yang di dapatkan dengan cara menjumlahkan nilai pasar dengan premium dan solatium. Setelah didapatkan hasilnya, appraisal menyerahkan pada BPN Padang Pariaman. Selanjutnya BPN akan menyampaikan kepada masyarakat. Saat proses penyampaian ini masyarakat merasa keberatan, karena menganggap bahwa nilai yang dikeluarkan oleh tim appraisal terlalu rendah, sementara menurut tim appraisal, mereka sudah melaksanakan tugas sesuai dengan Undang-Undang Pengadaan Tanah, Kode Etik Penilai Indonesia serta Standar Penilaian Indonesia.

\subsection{Musyawarah penetapan bentuk ganti kerugian}

Musyawarah dilakukan secara langsung untuk menetapkan bentuk ganti kerugian berdasarkan hasil penilaian ganti kerugian. Bentuk ganti kerugian dapat beruapa uang, tanah pengganti, pemukiman kembali, kepemilikan saham, dan bentuk lain yang disetujui kedua belah pihak. Dalam musyawarah penetapan bentuk ganti kerugian ini, masyarakat di Nagari Kasang sepakat untuk memilih bentuk ganti kerugian dalam bentuk uang.

\subsection{Pemberian ganti kerugian}

Pemberian ganti kerugian dalam bentuk uang dilakukan melalui jasa perbankan atau pemberian secara tunai yang disepakati antara pihak yang berhak dan instansi yang memerlukan tanah. Pemberian ganti kerugian dilakukan bersamaan dengan pelepasan hak serta dibuat berita acarnya. Pemberian ganti kerugian dalam bentuk selain uang sama nilainya dengan nilai ganti kerugian berbentuk uang. Penyerahan ganti kerugian dalam bentuk lain dibuat berita acara penyerahan. Dalam proses ini, PPK Pengadaan Tanah selaku instansi yang membutuhkan tanah sudah membayarkan ganti kerugian melalui bank kepada pihak yang berhak setelah keluarnya nilai oleh tim appraisal.

\subsection{Pemberian ganti kerugian dalam keadaan khusus}

Pada pelaksanaan pengadaan tanah untuk pembangunan jalan tol ruas Padang-Sicincin tidak terdapat pemberian ganti kerugian dalam keadaan khusus.

\subsection{Penitipan ganti kerugian}

Berdasarkan data yang di dapat dari BPN Kabupaten Padang Pariaman, ada sebanyak 95 bidang tanah yang sedang dititipkan ganti rugi nya di Pengadilan. Dan sebagian besar masyarakat Nagari Kasang belum mengambil uang ganti rugi karena masih tidak menerima nilai ganti kerugiannya. 


Tabel 1
Jumlah Bidang Tanah Dalam Pengadaan Tanah
\begin{tabular}{|l|l|c|} 
Untuk Pembangunan Jalan Tol Ruas Padang-Sicincin $(\mathbf{0 - 4 , 2} \mathbf{~ k m}), \mathbf{2 0 1 9}$ \\
\hline No & \multicolumn{1}{|c|}{ Keterangan } & Jumlah \\
\hline 1 & Ganti kerugian yang sudah dibayarkan & 9 bidang \\
\hline 2 & $\begin{array}{l}\text { Ganti kerugian yang dititipkan di Pengadilan } \\
\text { Negeri Pariaman }\end{array}$ & 95 bidang \\
\hline 3 & Tahap validasi (yang akan dibayarkan) & 3 bidang \\
\hline 4 & $\begin{array}{l}\text { Ganti kerugian yang akan di titipkan di } \\
\text { Pengadilan }\end{array}$ & 22 bidang \\
\hline
\end{tabular}

Sumber : BPN Kabupaten Padang Pariaman (2019).

\subsection{Pelepasan objek pengadaan tanah}

Proses ini dilakukan dihadapan Kepala Kantor Pertanahan setempat dan dilaksanakan bersamaan saat pemberian ganti kerugian dengan penyerahan bukti-bukti penguasaan atau kepemilikan objek pengadaan tanah. Pada tahap ini, pelepasan objek pengadaan tanah dilakukan oleh Kepala BPN Kabupaten Padang Pariaman dihadapan masyarakat yang tanahnya terkena pembangunan jalan tol ruas Padang-Sicincin di Nagari Kasang.

\subsection{Pemutusan hubungan hukum antara pihak yang berhak dengan objek pengadaan tanah}

Pada tahap ini, Ketua BPN Kabupaten Padang Pariaman sekaligus sebagai Ketua Pelaksana Pengadaan Tanah sudah menyampaikan pemberitahuan tentang hapusnya hubungan hukum pada Wali Nagari Kasang untuk selanjutnya dicatat dalam buku administrasi di kantor Wali Nagari Kasang, Kecamatan Batang Anai.

\subsection{Pendokumentasian peta bidang, daftar nominatif, dan data administrasi pengadaan tanah}

Pelaksana pengadaan tanah melakukan pengumpulan, pengelompokan, pengolahan dan penyimpanan data pengadaan tanah. Data pengadaan tanah disimpan, didokumentasikan, dan diarsipkan oleh Kepala Kantor Pertanahan setempat dalam bentuk data elektronik. Pada tahap terakhir ini, BPN Kabupaten Padang Pariaman menyimpan, mendokumentasikan, dan mengarsipkan data pengadaan tanah dalam bentuk data elektronik.

\section{KESIMPULAN}

Sesuai dengan teori yang penulis gunakan, yaitu Peraturan Kepala BPN RI Nomor 5 Tahun 2012 tentang Petunjuk Teknis Pelaksanaan Pengadaan Tanah yang merupakan turunan dari Undang-Undang Nomor 2 Tahun 2012 tentang Pengadaan Tanah Bagi Pembangunan Untuk Kepentingan Umum. Di dalam petunjuk teknis pelaksanaan pengadaan tanah ini, lebih rinci dijelaskan bagaimana prosedur dalam pengadaan tanah yang dilaksanakan oleh Badan Pertanahan Nasional.

Secara umum, penulis melihat pelaksanaan pengadaan tanah untuk pembangunan jalan tol PadangSicincin di Kabupaten Padang Pariaman yang sudah terlaksana sampai dengan 4,2 km di Nagari Kasang sudah cukup baik, namun dalam prosesnya kendala utama yang dihadapi belum menemukan upaya yang maksimal karena kurangnya koordinasi dan komunikasi antar pihak terlibat dalam proses pengadaan tanah. 


\section{SARAN}

Berdasarkan penelitian yang dilakukan, penulis menyarankan agar pemerintah pusat dan daerah maupun pihak-pihak yang terkait dengan pelaksanaan pengadaan tanah untuk pembangunan jalan tol ruas Padang-Sicincin agar dapat meningkatkan koordinasi dan komunikasi agar tidak terjadi kesalahpahaman yang menimbulkan permasalahan antar pihak yang terkait maupun masyarakat agar pembangunan jalan tol ruas Padang-Sicincin terlaksana dengan lancar.

\section{DAFTAR PUSTAKA}

[1] Ahmadi, R. (2014). Metode Penelitian Kualitatif. Yogyakarta: Ar-Ruzz Media.

[2] Bisnis.com. (n.d.). Warga Pariaman Minta Ganti Rugi Tol Padang-Pekanbaru Lebih Adil. Diakses Pada Tanggal 15 Maret 2019.

[3] CNN Indonesia. (n.d.). Pemerintah Pastikan Tol Padang-Pekanbaru Tetap Dibangun. Diakses Pada Tanggal 23 Juli 2019.

[4] Noor, A. (2019). Peranan Infrastruktur terhadap Pertumbuhan Ekonomi dan Implikasi pada Kebijakan Pembangunan di Kota Samarinda. 31(2), 359-366.

[5] Peraturan Kepala BPN Republik Indonesia Nomor 5 Tahun 2012 tentang Petunjuk Teknis Pelaksanaan Pengadaan Tanah. (2012).

[6] Sugiyono. (2017). Metode Penelitian Kuantitatif, Kualitatif, dan R\&D. Bandung: Alfabeta. 